\title{
Métodos de preservação in vitro de urediniósporos de Puccinia kuehnii
}

\author{
Fabiana Tibolla ${ }^{1}$; Ciro Hideki Sumida ${ }^{1}$; Douglas Casaroto Peit ${ }^{1}$, Marcelo Giovanetti Canteri ${ }^{1}$, Ana Maria Conte e \\ Castro $^{2}$.
}

\begin{abstract}
${ }^{1}$ Departamento de Agronomia, Universidade Estadual de Londrina, Cx. Postal 6001, CEP.86051-990, Londrina, PR, Brasil. ${ }^{2}$ Universidade Estadual do Norte do Paraná, CEP: 86360-000, Bandeirantes, PR.

Autor para correspondência: Marcelo Giovanetti Canteri (canteri@uel.br)

Data de chegada: 28/03/2012. Aceito para publicação em: 19/08/2012.
\end{abstract}

1810

\section{RESUMO}

Tibolla, F.; Sumida, C.H.; Peitl, D.C.; Canteri, M.G., Castro, A.M.C. Métodos de preservação in vitro de urediniósporos de Puccinia kuehnii. Summa Phytopathologica, v.38, n.3, p.198-203, 2012.

Com o objetivo de avaliar métodos de preservação de urediniósporos de Puccinia kuehnii, conduziram-se dois bioensaios sendo o primeiro (B1) com diferentes métodos de desidratação e o segundo (B2), com diferentes métodos de reidratação. Em B1 foi adicionado um grânulo de sílica gel para preservação dos urediniósporos nos tubos de microcentrífuga. Foram coletadas folhas com sintomas de ferrugem alaranjada, P. kuehnii, da cultivar de cana-de-açúcar SP89 1115. Os urediniósporos do agente causal de ferugem foram extraídos das folhas com o auxílio de bomba a vácuo. Posteriormente, estes foram acondicionados em tubos de microcentrífuga. Os tratamentos para B1 foram: 1- desidratação em sílica gel, liofilização e sem desidratação; 11- temperatura ambiente $\left(20^{\circ} \mathrm{C}\right)$, geladeira $\left(5^{\circ} \mathrm{C}\right)$, congelador $\left(-20^{\circ} \mathrm{C}\right)$ e deep-freezer $\left(-80^{\circ} \mathrm{C}\right)$. Para B2 os tratamentos foram: 1- desidratação em sílica gel e sem desidratação; 11- temperatura ambiente $\left(20^{\circ} \mathrm{C}\right)$, geladeira $\left(5^{\circ} \mathrm{C}\right)$, congelador $\left(-20^{\circ} \mathrm{C}\right)$ e deep-freezer $\left(-80^{\circ} \mathrm{C}\right)$; 111- com reidratação e sem reidratação nas avaliações. Para ambos os bioensaios foi realizada a germinação inicial, outras aos 15 e 30 dias de armazenamento e posteriormente a cada 30 dias, até 180 dias. Prepararam-se suspensões de urediniósporos em água e uma alíquota de $0,1 \mathrm{~mL}$ foi transferida para placas de Petri contendo meio ágar-água $\left(15 \mathrm{~g} \mathrm{~L}^{-1}\right)$. Essas permaneceram a $20^{\circ} \mathrm{C}$, no escuro. Para a avaliação da viabilidade, procedeu-se a contagem de 200 urediniósporos por placa. Os dados foram submetidos à análise de variância não paramétrica de Kruskal-Wallis e complementadas com o teste de Dunn. Os resultados demonstraram que a viabilidade decresceu em função do tempo, sendo que os melhores tratamentos atingiram $27,6 \%$ e $6,6 \%$ aos 30 dias, e $12,0 \%$ e $1,9 \%$ aos 60 dias, para B1 e B2, respectivamente. $\mathrm{O}$ método da desidratação em sílica gel seguido do armazenamento a $-80^{\circ} \mathrm{C}$ foi o único que apresentou urediniósporos viáveis $(1,2 \%)$ aos 180 dias, para B1. No B2, o melhor método foi preservação com desidratação, armazenados a $5^{\circ} \mathrm{C}$, sem reidratação. Esse método apresentou melhor porcentagem de germinação aos 120 dias $(0,4 \%)$. Não foi observada influência do fator choque térmico na recuperação de urediniósporos viáveis em B2. A inclusão de grânulo de sílica gel no tubo de microcentrífuga permitiu a recuperação da viabilidade dos urediniósporos aos 180 dias.

Palavras-chave adicionais: ferrugem alaranjada, liofilização, sílica gel, Saccharum officinarum, reidratação.

\section{ABSTRACT}

Tibolla, F.; Sumida, C.H.; Peitl, D.C.; Canteri, M.G., Castro, A.M.C. In vitro preservation methods of Puccinia kuehnii urediniospores. Summa Phytopathologica, v.38, n.3, p.198-203, 2012.

With the aim of evaluating preservation methods of Puccinia kuehnii urediniospores, two bioassays were conducted: the first one (B1) with different methods of dehydration and the second one (B2) with different methods rehydration. B1 and B2 differed in the inclusion of silica gel granule in B1 for preservation in microcentrifuge tubes. Leaves with symptoms of orange rust were harvested from the sugarcane cultivar SP89 1115. P. kuehnii urediniospores were extracted from the leaves with the aid of a vacuum bomb. Later, they were placed in microcentrifuge tubes. Treatments for B1 were: 1: dehydration in silica gel, lyophilization and without dehydration, 11: room temperature $\left(20^{\circ} \mathrm{C}\right)$, refrigerator $\left(5^{\circ} \mathrm{C}\right)$, freezer $\left(-20^{\circ} \mathrm{C}\right)$ and deep-freezer $\left(-80^{\circ} \mathrm{C}\right)$. Treatments for $\mathrm{B} 2$ were: 1: dehydration in silica gel and without dehydration, 11: room temperature $\left(20^{\circ} \mathrm{C}\right)$, refrigerator $\left(5^{\circ} \mathrm{C}\right)$, freezer $\left(-20^{\circ} \mathrm{C}\right)$ and deep-freezer $\left(-80^{\circ} \mathrm{C}\right)$, 111: with and without rehydration in the evaluations. The initial germination was carried out for both experiments, other assessments were made at 15 and 30 days of storage and then at every 30 days until 180 days. Urediniospore suspensions were prepared in water and a 0.1 $\mathrm{mL}$ aliquot was transferred to Petri dishes containing agar-water (15 $\left.\mathrm{g} \mathrm{L}^{-1}\right)$. They remained at $20^{\circ} \mathrm{C}$ in the dark. To assess viability, the count of 200 urediniospores/plate was performed. The data were subjected to nonparametric Kruskal-Wallis analysis of variance and complemented by Dunn's test. Results showed that viability decreased with time, and the best treatments reached $27.6 \%$ and $6.6 \%$ at 30 days, and $12.0 \%$ and $1.9 \%$ at 60 days for $\mathrm{B} 1$ and $\mathrm{B} 2$, respectively. Dehydration method in silica gel followed by storage at $-80^{\circ} \mathrm{C}$ was the only treatment that presented viable urediniospores (1.2\%) at 180 days for B1. For B2, the best method was preservation with dehydration, followed by storage at $5{ }^{\circ} \mathrm{C}$, without rehydration. This method showed the best germination percentage at 120 days $(0.4 \%)$. Influence of the factor thermal shock was not observed in the recovery of viable urediniospores in B2. Inclusion of silica gel granules in the microcentrifuge tube allowed the recovery of viability of urediniospores at 180 days.

Additional keywords: orange rust, lyophilization, preservation, silica gel, Saccharum officinarum, rehydration. 
As doenças desempenham importante papel no cultivo da canade-açúcar, pois acarretam severas perdas na produtividade. Dentre estas se destacam a ferrugem alaranjada, causada pelo fungo Puccinia kuehnii (W. Krüger) E.J. Butler e a ferrugem marrom (Puccinia melanocephala Syd. \& P. Syd) (13). Ambos os patógenos pertencem à classe dos Basidiomicetos, ordem Pucciniales e a família Pucciniaceae (12).

A ferrugem alaranjada está presente na maioria dos países produtores de cana-de-açúcar. O primeiro relato deste patógeno no continente americano foi nos Estados Unidos em 2007(4). Posteriormente foi relatada na Nicarágua, Panamá, Costa Rica, Guatemala, Venezuela, Cuba, México e El Salvador (3, 7, 13, 14, $16,18)$. No Brasil, a doença foi oficialmente detectada na região de Araraquara-SP, em 2009 (2).

A preservação de patógenos é necessária para se proceder a comparação entre diferentes espécies, identificação de novas raças, estudos laboratoriais, entre outros. Cada patógeno apresenta comportamento diferente às técnicas utilizadas na preservação. Devendo-se levar em consideração as características que se deseja preservar, desde a viabilidade, manutenção de características morfológicas, até pureza dos isolados (9).

Para os fungos causadores de ferrugens em plantas, os métodos que envolvem desidratação seguida de armazenamento em baixas temperaturas, são os que apresentam melhores resultados na manutenção da viabilidade (9). Zambenedetti et al.(20), testou esses metodos para urediniósporos de Phakopsora pachyrhizi Syd \& P. Syd, e concluíram que o mais eficiente para este patógeno foi o nitrogênio líquido.

Resultados semelhantes foram obtidos por Salustiano et al. (19), em ensaios realizados com Puccinia psidii G., nos quais os urediniósporos deste agente causal de ferrugem foram armazenados em condições de baixas temperaturas, tendo assim suas estruturas infectivas e viabilidade foram preservadas.

Pesquisas realizadas com Puccinia graminis f.sp. tritici Erikss. \& Henning, Puccinia triticina Erikss e Puccinia striiformis f.sp. tritici Erikss, demonstraram que a utilização de folhas, caule e plântulas foram eficientes na preservação de urediniósporos de ferrugens (11).

Menzies et al. (15) realizaram ensaio utilizando coleções de isolados de Ustilago tritici (Pers.) E. Rostr. Sementes inoculadas com o patógeno foram armazenadas em dessecador com sílica gel na temperatura de $-15^{\circ} \mathrm{C}$. Eles concluíram que das sementes que produziram plantas adultas entre 56 e $98 \%$ mostraram sintomas da doença durante os 20 anos de testes.

Assim o presente estudo teve como objetivo testar diferentes métodos para preservação de fungos biotróficos e verificar a eficiência dos mesmos para a preservação da viabilidade dos urediniósporos de P. kuehnii.

\section{MATERIAL E MÉTODOS}

Preservação de urediniósporos de Puccinia kuehnii com diferentes métodos de desidratação

Os urediniósporos de P. kuehnii foram obtidos de folhas com sintomas de ferrugem alaranjada da variedade de cana-de-açúcar SP891115, coletadas ao acaso em plantas com idade de 9-10 meses, estando à área localizada no município de Andirá, PR. Posteriormente foram encaminhadas ao Laboratório de Fitopatologia da Universidade Estadual de Londrina, onde permaneceram em câmara úmida por 24 horas, a $25^{\circ} \mathrm{C}$, para favorecer a esporulação.

Os urediniósporos de $P$. kuehnii. foram extraídos das folhas com o auxílio de bomba a vácuo (FANEM, modelo:089-cal; potência: 550Watts; série: BF 7403), adaptou-se um Kitasato na extremidade da mangueira para deposição dos urediniósporos. Posteriormente, estes foram peneirados em malha de 200 mesh, e acondicionados em tubos de microcentrífuga $(0,7 \mathrm{mg} /$ tubo). Os tratamentos, em esquema fatorial com dois fatores, foram compostos por: 1- desidratação em sílica gel (24 horas em dessecador a $20^{\circ} \mathrm{C}$, e um grânulo de sílica gel em cada tubo de microcentrífuga), liofilizador ( 6 horas em liofilizador a $\left.-40^{\circ} \mathrm{C}\right)$, sem desidratação; 11- temperatura ambiente $\left(20^{\circ} \mathrm{C}\right)$, geladeira $\left(5^{\circ} \mathrm{C}\right)$, congelador $\left(-20^{\circ} \mathrm{C}\right)$ e deepfreezer $\left(-80^{\circ} \mathrm{C}\right)$.

Avaliou-se a germinação inicial antes de submeter os urediniósporos aos tratamentos. Preparou-se uma suspensão de urediniósporos em água destilada, esterilizada, e uma alíquota de 0,1 $\mathrm{mL}$ foi transferida para placas de Petri contendo meio ágar-água $(15 \mathrm{~g}$ $\left.\mathrm{L}^{-1}\right)$. As placas inoculadas foram mantidas na temperatura de $20^{\circ} \mathrm{C}$, no escuro, em B.O.D. A germinação foi interrompida após 24h, utilizandose lactofenol, e avaliada em 200 urediniósporos/placa, em cinco placas, com o auxílio de microscópio ótico.

Realizaram-se outras avaliações com 15 e 30 dias de armazenamento, e posteriormente avaliações a cada 30 dias até completar 180 dias de armazenamento. Para a avaliação de viabilidade, os urediniósporos foram reidratados lentamente, deixando-se os tubos de microcentrífuga abertos por 4 horas em câmara úmida. Para esta utilizou-se caixa transparente tipo Gerbox $(15 \times 15 \mathrm{~cm})$ com papel para germinação umedecido com água destilada e esterilizada. Em seguida, prepararam-se suspensões de urediniósporos em água destilada e esterilizada, uma alíquota de $0,1 \mathrm{~mL}$ foi transferida para placas de Petri contendo meio ágar-água $\left(15 \mathrm{~g} \mathrm{~L}^{-1}\right)$. Cada unidade experimental foi composta por uma placa de Petri. Cada tratamento foi composto por cinco repetições. As placas inoculadas foram mantidas na temperatura de $20^{\circ} \mathrm{C}$, no escuro, em B.O.D. A germinação foi interrompida após $24 \mathrm{~h}$, utilizando-se lactofenol.

Avaliou-se a germinação de 200 urediniósporos/placa, com o auxílio de microscópio ótico. Consideraram-se como urediniósporos germinados aqueles que apresentaram tubo germinativo maior que o seu diâmetro.

Preservação de urediniósporos de Puccinia kuehnii com diferentes métodos de reidratação

Os urediniósporos de ferrugem alaranjada foram obtidos e processados segundo o mesmo método do bioensaio anterior. Posteriormente, esses foram acondicionados em tubos de microcentrífuga ( $0,2 \mathrm{mg} /$ tubo). Os tratamentos, em esquema fatorial com 3 fatores, foram: 1- desidratação em sílica gel $(24 \mathrm{~h}$ em dessecador a $\left.20^{\circ} \mathrm{C}\right)$ e sem desidratação; $11-$ temperatura ambiente $\left(20^{\circ} \mathrm{C}\right)$, geladeira $\left(5^{\circ} \mathrm{C}\right)$, congelador $\left(-20^{\circ} \mathrm{C}\right)$ e deep-freezer $\left(-80^{\circ} \mathrm{C}\right)$; 11l: com reidratação e sem reidratação (câmara úmida por 24h). As avaliações foram iguais ao bioensaio anterior. Porém cessadas aos 150 dias após o armazenamento. E sendo cada unidade experimental composta por uma placa de Petri e cada tratamento composto por oito repetições.

\section{Análise dos Dados}

Os dados foram submetidos à análise de variância não paramétrica de Kruskal-Wallis, e complementados com o teste de Dunn, para identificação de diferenças significativas entre as amostras, duas a duas. Os dados foram analisados no programa Bioestat versão 5.0 (1). 


\section{RESULTADO E DISCUSSÃO}

\section{Preservação de urediniósporos de Puccinia kuehnii com diferentes métodos de desidratação}

Os resultados obtidos no bioensaio de preservação de urediniósporos de P. kuehnii, com diferentes métodos de desidratação, demonstraram que a porcentagem de viabilidade dos urediniósporos de ferrugem alaranjada decresceu em função do tempo, independente dos tratamentos testados (Tabela 1).

Os urediniósporos desidratados em sílica gel, preservados a $20^{\circ} \mathrm{C}$, apresentaram maior porcentagem de germinação aos 15 dias de armazenamento. Este tratamento diferiu significativamente $(\mathrm{p}<0,01)$ dos tratamentos onde os urediniósporos foram desidratados em liofilizador e preservados a $20^{\circ} \mathrm{C}, 5^{\circ} \mathrm{C} \mathrm{e}-20^{\circ} \mathrm{C}$.

Os urediniósporos desidratados em liofilizador, preservados a $20^{\circ} \mathrm{C}$, também foram significativamente $(\mathrm{p}<0,01)$ diferentes dos urediniósporos sem desidratação, preservados a $-80^{\circ} \mathrm{C}$. Já os urediniósporos de ferrugem alaranjada submetidos à desidratação em liofilizador, preservados a $20^{\circ} \mathrm{C}$, foram os que apresentaram menor porcentagem média de germinação na avaliação aos 15 dias após o armazenamento.

$\mathrm{Na}$ avaliação aos 30 dias de armazenamento foi possível constatar diferenças significativas $(\mathrm{p}<0,01)$ entre os urediniósporos submetidos à desidratação em sílica gel, preservados a $20^{\circ} \mathrm{C}$ e os urediniósporos submetidos a desidratação em sílica gel preservados a $5^{\circ} \mathrm{C}$, liofilizados preservados a $20^{\circ} \mathrm{C}$ e sem desidratação preservados a $20^{\circ} \mathrm{C}$. Os urediniósporos desidratados em sílica gel, preservados a $20^{\circ} \mathrm{C}$ apresentaram melhores taxas de viabilidade no período analisado. Os urediniósporos desidratados em sílica gel e armazenados a $5^{\circ} \mathrm{C}$ apresentaram menor porcentagem média de germinação.

Aos 60 dias após o armazenamento, o número de tratamentos que diferiram foi superior aos das avaliações anteriores (tabela 1). Neste período de armazenamento, os urediniósporos que apresentaram melhores porcentagens de germinação foram os que não receberam desidratação, preservados a $-80^{\circ} \mathrm{C}$. Os urediniósporos desidratados em liofilizador preservados a $20^{\circ} \mathrm{C}$ e $-20^{\circ} \mathrm{C}$ e os urediniósporos sem desidratação preservados a $5^{\circ} \mathrm{C}$ não apresentaram germinação $(\mathrm{p}<0,01)$.

Com 90 dias de armazenamento, os urediniósporos sem desidratação preservados a $-80^{\circ} \mathrm{C}$ obtiveram as melhores taxas de germinação. Este tratamento diferiu significativamente (pd"0,03) dos tratamentos onde os urediniósporos foram desidratados em liofilizador, preservados a $-80^{\circ} \mathrm{C}$, e também dos urediniósporos sem desidratação preservados a $20^{\circ} \mathrm{C}, 5^{\circ} \mathrm{C} \mathrm{e}-20^{\circ} \mathrm{C}$. Nestes tratamentos a porcentagem de germinação foi igual a zero.

A partir da $4^{\mathrm{a}}$ avaliação (90 dias) não foi possível observar diferença significativa $(\mathrm{p}<0,05)$ entre os tratamentos devido ao elevado número de médias iguais ou próximas a zero em todos os tratamentos analisados. Os urediniósporos de $P$. kuehnii submetidos à desidratação em sílica gel e preservados $\mathrm{a}-80^{\circ} \mathrm{C}$ apresentou os melhores resultados ao longo do período de armazenamento (180 dias). Apesar da brusca queda de germinação em relação à porcentagem inicial, 36 pontos percentuais a menos, este foi o único tratamento que apresentou germinação em todos os períodos avaliados (Figura 1).

Analisando os tratamentos por avaliação, foi possível observar que para os 15 e 30 dias de armazenamento, os urediniósporos que apresentaram melhores porcentagens de germinação foram os submetidos à desidratação em sílica gel preservados a $20^{\circ} \mathrm{C}$. A porcentagem média observada aos 15 dias foi de $25,6 \%$, valor, em média, 17 pontos percentuais superior aos demais tratamentos testados. Na avaliação de 30 dias a porcentagem média foi de $27,6 \%$, em torno de 16 pontos percentuais, acima dos demais tratamentos analisados.

Nas avaliações realizadas aos 60 e 90 dias após o armazenamento, os urediniósporos sem desidratação, preservados a $-80^{\circ} \mathrm{C}$ tiveram acréscimo médio de 10 pontos percentuais aos 60 dias. Aos 90 dias a porcentagem de todos os tratamentos teve queda acentuada na germinação, valores estes iguais ou próximos a zero. Os urediniósporos sem desidratação, seguidos de armazenamento a $-80^{\circ} \mathrm{C}$ apresentaram em média 2,5 pontos percentuais acima da média geral dos demais tratamentos.

Tabela 1. Porcentagem de germinação de urediniósporos de $P$. kuehnii (ferrugem alaranjada), após armazenamento por periódos de 15, 30, 60, $90,120,150$ e 180 dias.

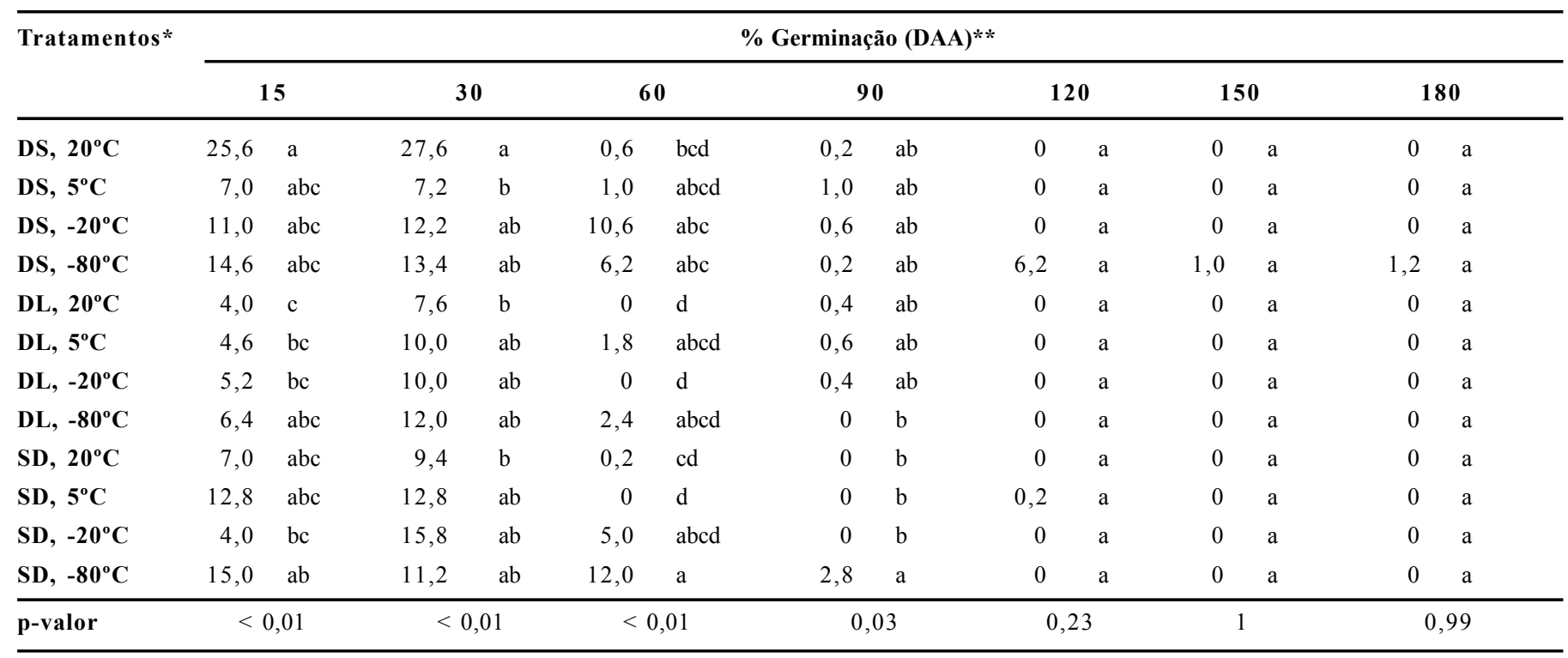

*Desidratados em silica gel (DS), desidratados em liofilizador (DL) e sem desidratação (SD), em temperaturas de $20,5,-20$ e $-80^{\circ}$ C. ** DAA: Dias Após o Armazenamento. ***Médias seguidas de mesma letra na coluna não diferem entre si pelo teste de Dunn $(\mathrm{p}<0,05)$. 


\section{Sílica Gel (A)}

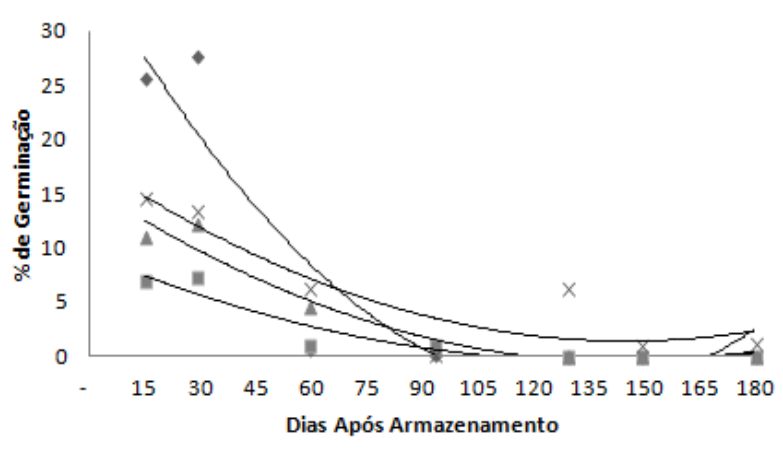

Liofilização

(B)

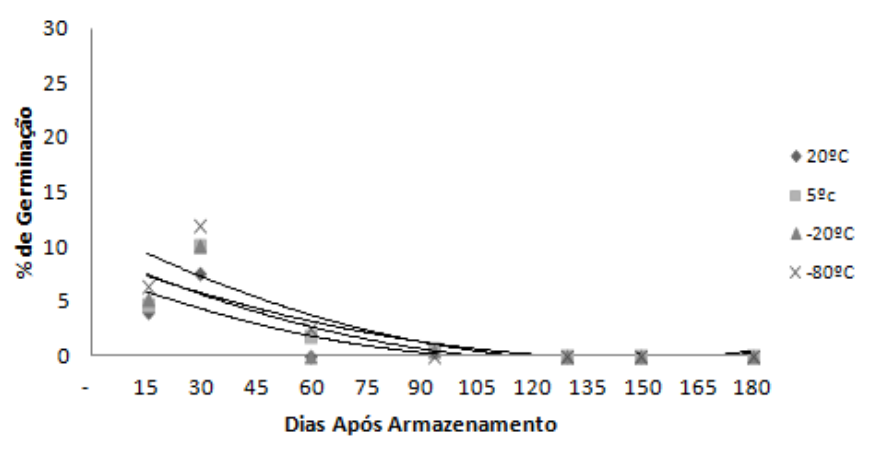

Sem Desidratação (C)

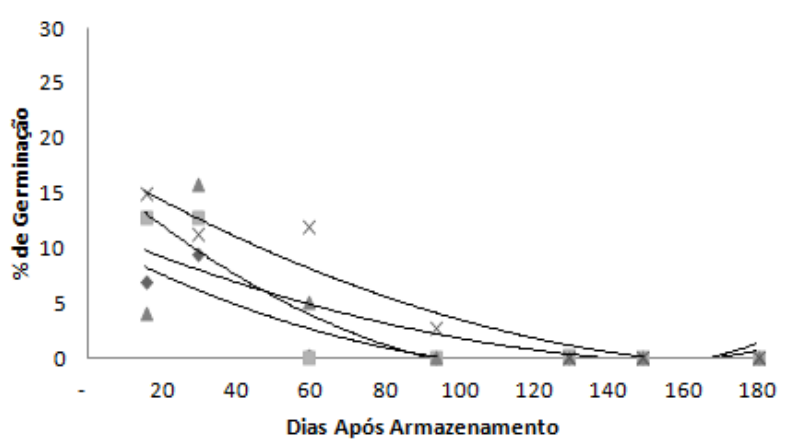

Figura 1. Germinação in vitro de urediniósporos de $P$. kuehnii em função do tempo de armazenamento, sobre quatro temperaturas $\left(20^{\circ} \mathrm{C}, 5^{\circ} \mathrm{C}-20^{\circ} \mathrm{C}\right.$ e $-80^{\circ} \mathrm{C}$ ) e três diferentes desidratações: sílica gel (A), liofilização(B) e sem desidratação(C).

Os resultados do bioensaio corroboram com os resultados alcançados por outros autores $(5,6,9,10,15,17,19,20)$ para preservação de fungos, parasitas obrigatórios de plantas. Teste semelhante a este foi realizado com urediniósporos de $P$. melanocephala, no qual os autores observaram que a preservação dos urediniósporos a baixas temperaturas $\left(-20^{\circ} \mathrm{C} \mathrm{e}-80^{\circ} \mathrm{C}\right)$, antecedidos de desidratação em sílica gel, manteve a viabilidade por um período de até um ano de armazenamento (10).

Resultados semelhantes foram obtidos por Pérez-García et al. (17) testando diferentes técnicas de armazenamento de Podosphaera fusca (Fr.). Os autores observaram que a desidratação em sílica gel seguida de armazenamento em deep-freezer $\left(-80^{\circ} \mathrm{C}\right)$ foi o método mais viável.
Faleiro et al. (6) verificaram que a germinação de urediniósporos de Uromyces appendiculatus Pers, decresceu rapidamente em todas as temperaturas testadas. Ensaios realizados com P. psidii G., sobre diferentes temperaturas de armazenamento, mostraram que o fungo se manteve viável, e suas estruturas infectivas foram preservadas. Os tratamentos nitrogênio líquido $\left(-196^{\circ} \mathrm{C}\right)$, deep-freezer $\left(-80^{\circ} \mathrm{C}\right)$ e geladeira $\left(5^{\circ} \mathrm{C}\right)$ foram os que apresentaram melhores resultados ao final do período de preservação. Estes tratamentos mantiveram os urediniósporos viáveis e infectivos por um período de até 150 dias após o armazenamento (19).

Zambenedetti et al.(20) avaliaram o efeito de diferentes métodos de armazenamento na viabilidade de urediniósporos de P. pachyrhizi. Os autores testaram o armazenamento de folhas herborizadas com urediniósporos $\left(24^{\circ} \mathrm{C}\right)$, armazenamento de urediniósporos em dessecador $\left(10^{\circ} \mathrm{C}\right)+$ nitrogênio líquido $\left(-196^{\circ} \mathrm{C}\right)$, em geladeira $\left(4^{\circ} \mathrm{C}\right)$, deep-freezer $\left(-80^{\circ} \mathrm{C}\right)$ e em nitrogênio líquido e concluíram que o melhor métodos para o armazenamento deste patógeno foi o nitrogênio líquido.

Menzies et al. (15) avaliaram a viabilidade de coleções de isolados de $U$. tritici, provenientes de diversas partes do mundo. Inocularam o patógeno em espiguetas de trigo em 1976, após o amadurecimento, as sementes foram armazenadas em dessecador com sílica gel na temperatura de $-15^{\circ} \mathrm{C}$. Os autores concluíram que entre 57 e $83 \%$ das sementes produziram plantas de trigo adultas e destas, entre $56 \mathrm{e}$ 98\% apresentaram sintomas da doença durante os 20 anos de testes.

Os trabalhos citados corroboram, com os resultados obtidos neste bioensaio, constatou-se que o método mais adequado para preservação depende do período em dias que se deseja preservar os urediniósporos. Para períodos superiores a 90 dias o método que preservou a viabilidade dos urediniósporos de $P$. kuehnii foi a desidratação em sílica gel seguida de armazenamento a $-80^{\circ} \mathrm{C}$.

\section{Preservação de urediniósporos de Puccinia kuehnii com diferentes métodos de reidratação}

Inicialmente, este bioensaio foi planejado em delineamento fatorial com 4 fatores, ou seja, além dos fatores temperatura, desidratação e reidratação, havia também o fator choque térmico (com e sem). O choque térmico foi executado mantendo os tubos de microcentrífuga contendo os urediniósporos a $40^{\circ} \mathrm{C} / 5 \mathrm{~min}$ antes da avaliação da germinação (9). Porém em função da utilização da análise não paramétrica houve necessidade da redução do número de tratamentos totais para aplicação do teste de Dunn. Assim, procedeu-se o teste de Mann-Whitney, que visou verificar a existência de diferenças dentro de cada fator, isoladamente, e desta forma desconsiderar nas análises o fator que não apresentou diferença entre os níveis testados.

Com a realização do teste de Mann-Whitney, verificou-se que o fator choque térmico não apresentou diferenças significativas $(p<0,05)$. Desta forma foram excluídos os tratamentos com choque térmico, das análises posteriores.

Os resultados do ensaio de preservação de urediniósporos de $P$. kuehnii com diferentes métodos de reidratação demonstraram que a porcentagem de germinação e viabilidade dos urediniósporos de ferrugem alaranjada, decresceu ao longo do período analisado (Tabela 2).

Os urediniósporos sem desidratação em sílica gel, preservados a $20^{\circ} \mathrm{C}$ e submetidos a reidratação antes da avaliação, apresentaram maior porcentagem de germinação aos 15 dias de armazenamento. Esse tratamento foi semelhante aos urediniósporos submetidos à desidratação em sílica gel, preservados a $5^{\circ} \mathrm{C}$, com reidratação; desidratação em sílica gel, preservados a $-20^{\circ} \mathrm{C}$, com reidratação; sem desidratação em sílica gel, preservados a $-80^{\circ} \mathrm{C}$, com e sem reidratação. 
Tabela 2. Porcentagem de germinação de urediniósporos de $P$. kuehnii (ferrugem alaranjada), após armazenamento por periódos de $15,30,60,90,120$ e 150 dias.

\begin{tabular}{|c|c|c|c|c|c|c|c|c|c|c|c|c|}
\hline \multirow{2}{*}{$\begin{array}{l}\text { Tratamentos* } \\
20^{\circ} \mathrm{C}, \mathrm{CD}, \mathrm{CR}\end{array}$} & \multicolumn{12}{|c|}{ \% Germinação (DAA)** } \\
\hline & \multicolumn{2}{|c|}{15} & \multicolumn{2}{|c|}{30} & \multicolumn{2}{|c|}{60} & \multicolumn{2}{|c|}{90} & \multicolumn{2}{|c|}{120} & \multicolumn{2}{|c|}{150} \\
\hline $20^{\circ} \mathrm{C}, \mathrm{CD}, \mathrm{SR}$ & 3,75 & $\mathrm{bc}$ & 3,13 & a & 0,13 & a & 0,00 & a & 0,00 & a & 0 & a \\
\hline $20^{\circ} \mathrm{C}, \mathrm{SD}, \mathrm{CR}$ & 3,06 & $\mathrm{bc}$ & 4,19 & a & 0,00 & a & 0,00 & a & 0,00 & a & 0 & a \\
\hline $20^{\circ} \mathrm{C}, \mathrm{SD}, \mathrm{SR}$ & 2,50 & $\mathrm{c}$ & 5,63 & a & 0,00 & $\mathrm{a}$ & 0,00 & a & 0,00 & a & 0 & a \\
\hline $5^{\circ} \mathrm{C}, \mathrm{CD}, \mathrm{SR}$ & 3,19 & $\mathrm{bc}$ & 3,63 & $\mathrm{a}$ & 0,00 & a & 0,38 & a & 0,38 & $\mathrm{a}$ & 0 & a \\
\hline $5^{\circ} \mathrm{C}, \mathrm{SD}, \mathrm{CR}$ & 3,75 & $\mathrm{bc}$ & 3,75 & a & 0,00 & a & 0,00 & $\mathrm{a}$ & 0,00 & $\mathrm{a}$ & 0 & a \\
\hline $\mathbf{5}^{\circ} \mathrm{C}, \mathrm{SD}, \mathrm{SR}$ & 2,88 & $\mathrm{bc}$ & 4,44 & a & 1,00 & a & 0,75 & $\mathrm{a}$ & 0,00 & a & 0 & a \\
\hline$-20^{\circ} \mathrm{C}, \mathrm{CD}, \mathrm{CR}$ & 5,06 & $a b c$ & 5,94 & a & 0,00 & $\mathrm{a}$ & 0,13 & $\mathrm{a}$ & 0,00 & $\mathrm{a}$ & 0 & a \\
\hline$-20^{\circ} \mathrm{C}, \mathrm{CD}, \mathrm{SR}$ & 2,88 & $\mathrm{bc}$ & 5,38 & a & 0,88 & $\mathrm{a}$ & 0,25 & $\mathrm{a}$ & 0,00 & $\mathrm{a}$ & 0 & a \\
\hline$-80^{\circ} \mathrm{C}, \mathrm{CD}, \mathrm{SR}$ & 3,50 & $\mathrm{bc}$ & 6,63 & a & 0,13 & $\mathrm{a}$ & 0,00 & $\mathrm{a}$ & 0,00 & $\mathrm{a}$ & 0 & a \\
\hline$-80^{\circ} \mathrm{C}, \mathrm{SD}, \mathrm{CR}$ & 4,88 & $a b c$ & 2,94 & a & 0,25 & a & 0,13 & a & 0,00 & a & 0 & a \\
\hline$-80^{\circ} \mathrm{C}, \mathrm{SD}, \mathrm{SR}$ & 4,94 & $a b c$ & 5,69 & $\mathrm{a}$ & 0,25 & $\mathrm{a}$ & 0,63 & $\mathrm{a}$ & 0,00 & a & 0 & $\mathrm{a}$ \\
\hline p- valor & $<0,001$ & 0,003 & 0,068 & 0,973 & 1 & 1 & & & & & & \\
\hline
\end{tabular}

*Desidratados (CD) ou sem (SD) desidratação em sílica gel e com (CR) ou sem reidratação (SR), em temperaturas de 20, 5, -20 e $-80{ }^{\circ} \mathrm{C} . * *$ DAA: Dias Após o Armazenamento. ***Médias seguidas de mesma letra na coluna não diferem entre si pelo teste de Dunn $(\mathrm{p}<0,05)$.

Para os demais tratamentos, a porcentagem de germinação dos urediniósporos sem desidratação em sílica gel, preservados a $-20^{\circ} \mathrm{C}$ e submetidos a reidratação foram significativamente $(\mathrm{p}<0,05)$ superiores.

O tratamento sem desidratação em sílica gel, preservado a $20^{\circ} \mathrm{C}$, sem reidratação apresentou menores taxas de germinação no período de 15 dias após o armazenamento, 40 pontos percentuais a menos que a porcentagem média obtida no início do bioensaio. Aos 30 dias de armazenamento, não foi possível constatar diferenças significativas $(\mathrm{p}<0,05)$ entre os tratamentos, dois a dois, pelo teste de Dunn.

A partir dos 60 dias após armazenamento, foram constatados valores médios iguais ou próximos de zero. Não sendo possível detectar diferenças significativas $(\mathrm{p}<0,05)$, entre os tratamentos.

Os resultados demonstraram que a viabilidade dos urediniósporos decresceu em relação a porcentagem inicial (43\%), sendo que os melhores tratamentos atingiram $6,63 \%$ aos 30 dias e $1,88 \%$ aos 60 dias (Tabela 2). Apesar de ausência de diferenças significativas $(\mathrm{p}<0,05)$ a partir dos 30 dias, os urediniósporos desidratados, preservados a $5^{\circ} \mathrm{C}$, sem reidratação e os urediniósporos sem desidratação, preservados a $-20^{\circ} \mathrm{C}$, com reidratação apresentaram viabilidade ao longo do período de 120 dias, $0,38 \%$ e $0,13 \%$, respectivamente.

A preservação de patógenos parasitas obrigatórios de plantas tem sido estudada ao longo dos anos. Os dados obtidos no presente trabalho estão de acordo com os dados alcançados por outros pesquisadores $(5,6,9,10,15,17,19,20)$ para preservação destes patógenos. A preservação em baixas temperaturas, antecedidas de diferentes métodos de desidratação, vem sendo empregada com sucesso para preservação destes patógenos por períodos prolongados.

Furtado et al. (9) compararam diferentes temperaturas e procedimentos de reversão de dormência para urediniósporos de $P$. pachyrhizi. Os tratamentos testados foram: temperatura ambiente, $5^{\circ} \mathrm{C},-20^{\circ} \mathrm{C}$ e $-80^{\circ} \mathrm{C}$, urediniósporos desidratados e não desidratados, reversão de dormência com choque térmico $\left(40^{\circ} \mathrm{C} / 5 \mathrm{~min}\right.$.) e com reidratação (câmara úmida/24h). Urediniósporos armazenados em temperatura ambiente não sobreviveram mais que um mês independentemente da hidratação. Já os urediniósporos armazenados a baixas temperaturas tiveram sua viabilidade aumentada em função da desidratação. Dentre os tratamentos que passaram pelo choque térmico, os que foram armazenados a $-80^{\circ} \mathrm{C}$ e que envolveram hidratação alcançaram de 85 a $92 \%$ da germinação inicial.

Resultados semelhantes foram observados no presente bioensaio, onde urediniósporos armazenados a $20^{\circ} \mathrm{C}$ apresentaram baixa porcentagem de germinação aos 60 dias $(0,50 \%, 0,13 \%, 0 \%$ e $0 \%)$, nos quatro tratamentos. Chegando a zero nos demais períodos avaliados, independentemente da desidratação e reidratação. Os urediniósporos armazenados em baixas temperaturas, $5^{\circ} \mathrm{C} \mathrm{e}-20^{\circ} \mathrm{C}$, apresentaram melhores taxas de viabilidade aos 120 dias de armazenamento. Ao contrário do que foi observado por Furtado (9), os tratamentos que passaram por choque térmico não apresentam diferenças significativas $(\mathrm{p}<0,05)$.

Furtado et al. (8), utilizaram urediniósporos de P. pachyrhizi, submetidos o método de preservação proposta por Furtado et al. (9) modificada. Esta consiste em desidratar os urediniósporos em sílica gel (dessecador $/ 24 \mathrm{~h}$ ), armazenar a $-80^{\circ} \mathrm{C}$, submetê-los ao choque térmico $\left(40^{\circ} \mathrm{C} / 1 \mathrm{~min}\right)$ e reidratá-los (câmara úmida/16 h). Constatou-se com o trabalho, que o método empregado na preservação dos urediniósporos foi adequada, possibilitando a realização de outros experimentos in vitro.

Assim como nos trabalhos citados, com os resultados obtidos nesse bioensaio, pode-se observar que o método mais eficiente para preservação, a curtos períodos de tempo, foram aqueles onde os urediniósporos de $P$. kuehnii foram desidratados, armazenado em baixas temperaturas e reidratados. 
Os ensaios foram realizados em intervalo de 5 dias de diferença, sendo que a porcentagem inicial de germinação foi de $43,5 \%$ para o primeiro bioensaio e $43,2 \%$ para o segundo bioensaio.

Nos tratamentos que passaram pela desidratação em sílica gel e posteriormente reidratação, a porcentagem de germinação foi maior no primeiro bioensaio para todas as temperaturas testadas. Os resultados demonstraram que as taxas de viabilidade dos urediniósporos aos 30 dias foram de: $27,6 \%$ e $4,0 \%$ em $20^{\circ} \mathrm{C}, 7,2 \%$ e $3,1 \%$ em $5^{\circ} \mathrm{C}, 12,2 \%$ e $6,0 \%$ em $-20^{\circ} \mathrm{C}$ e $13,4 \%$ e $4,0 \%$ em $-80^{\circ} \mathrm{C}$, para primeiro e segundo bioensaios, respectivamente.

Isso pode ter ocorrido, devido ao fato de que no primeiro bioensaio, após a desidratação em dessecador de sílica gel, os tubos de microcentrífuga contendo os urediniósporos receberam um grânulo de sílica gel, antes de serem lacrados. No segundo bioensaio não foram adicionados aos tubos de microcentrífuga o grânulo de sílica gel. Essa variação no método pode explicar o fato da viabilidade dos urediniósporos terem sido menores nesse bioensaio do que no primeiro.

Aos 30 dias de armazenamento comparando os resultados de germinação do melhor tratamento do primeiro bioensaio, com os resultados do segundo bioensaio para o mesmo tratamento, constatouse um incremento de 23,6 pontos percentuais a preservação de urediniósporos que continham o grânulo de sílica gel.

Conclui-se com o presente trabalho que a desidratação de urediniósporos em sílica gel, com a inclusão do grânulo deste material no tubo de microcentrífuga, seguido do armazenamento a $-80^{\circ} \mathrm{C}$ foi o método que preservou a viabilidade dos urediniósporos de $P$. kuehnii até os 180 dias $(1,2 \%)$. O fator choque térmico não apresentou influência na recuperação de urediniósporos viáveis, neste bioensaio.

\section{AGRADECIMENTO}

Os autores agradecem a CAPES pela concessão de bolsa de pósgraduação ao primeiro autor. Ao programa de Pós-graduação em Agronomia-UEL e a todos que de alguma forma contribuíram para realização deste trabalho.

\section{REFERÊNCIAS BIBLIOGRÁFICAS}

1. Ayres, M.; Ayres Jr, M.; Ayres, D. L.; Santos, A.A.S.; Bioestat: aplicações estatísticas nas áreas das ciências biomédicas. Belém: 2007, p 324.

2. Barbasso, D.; Jordão, H.; Maccheroni, W.; Boldini, J; Sanguino, A.; First report of Puccinia kuehnii, causal agente of orange rust of sugarcane, in Brazil. Plant Disease, Saint Paul, v.94, n.9, p. 1170 , Set. 2010.

3. Chavarría, E.; Subirós, F.; Vega, J.; Ralda, G.; Glynn, N.C.; Comstock, J. C.; Castlebury, L.A. 1. First report of orange rust of sugarcane caused by Puccinia kuehnii in Costa rica and Nicaragua. Plant Disease, Saint Paul, v.93, n.4, p.425, Abril. 2009.

4. Comstock, J.C.; Sood, S.G.; Glynn, N.C.; Shine Jr, J. M; McKemy, J. M; Castlebury, L. A. First report of Puccinia kuehnii, causal agent of orange rust of sugarcane, in the United States and western hemisphere. Plant Disease, Saint Paul v.92, n.1, p.175, jan. 2008.

5. Cruz, J.C.S.; Souza, N.L.; Padovani, C.R.; Furtado, E.L.; Preservação do inóculo de Plasmodiophora brassicae utilizando o mé- todo de congelamento. Summa Phytopathologica, Botucatu, v.35, n.1, p.57-59, 2009.

6. Faleiro, F.G.; Ragamin, V.A.; Vinhadelli, W.S.; Mesquita, A.G.G.; Moreira, M.A.; Barros, E.G.; Redução da capacidade de infecção de urediniósporos de Uromyces appendiculatus após o armazenamento em diferentes condições. Fitopatologia Brasileira, Brasília - DF, v.25, n.1, p.98-100, 2000

7. Flores, R.C.; Loyo, J.R.; Ojeda, R.A.; Rangel, O.C.A.; Cerón, F.A.; Márquez, W.; Guerra-Moreno, A.S.; Hernandez-Ibarra, H.M.; González, R.E.; Castlebury, L.A.; Dixon, L.J.; Glynn, N.C.; Comstock, J.C.; Flynn, J.; Amador, J. First report of orange rust of sugarcane caused byPuccinia kuehnii in Mexico, El Salvador, and Panama. Plant Disease, Saint Paul, v.93, n.12, p.1347, dec. 2009

8. Furtado, G. Q.; Alves, S. A. M.; Godoy, C. V.; Salatino, M. L.F.; Massola Jr, N. S.; Influência da luminosidade e da camada de cera epicuticular de superfícies de folhas de soja na infecção de Phakopsora pachyrhizi, Tropical Plant Pathology, Brasilia-DF, v. 34, n.5, p.306-312, 2009.

9. Furtado, G. Q.; Alves, S.A. M.; Czermainski, A. B. C.; Massola Jr, N. S.; Preservation of Phakopsora pachyrhizi Uredospores, Journal of Phytopathology, Bari, n.156, p.62-64, 2008.

10. Garcia, E.O.; Casagrande, M.V.; Rago, A.M.; Massola Jr, N.S.; Preservação de urediniósporos de Puccinia melanocephala, agente causal de ferrugem em cana-de-açúcar. Summa Phytopathologica, Botucatu, v.33, n.2, p.1-9, 2007.

11. Imbaby, I. A.; Nazarim, M.; Ali, M. M.; Nagwa, I. A.; Viability of Wheat Rust Urediniospores Produced on Different Stages of Susceptible Plants, Egyptian Journal Phytopathology, Orman, v. 33, n.1, p.59-76, 2005.

12. Index Fungorum: Disponível em: $<\mathrm{http}: / / \mathrm{www}$.indexfungorum.org/ Names/NamesRecord.asp?RecordID=243512>. Acesso em: 09 Ago. 2011

13. Infante, D.; Martinez, B.; Gonzalez, E.; Gonzalez, N.; Puccinia kuehnii (KRÜGER) butler y Puccinia melanocephala H. sydow y P. sydow en el cultivo de la caña de azúcar. Revista Protección Vegetal. Cuba, v.24. p.22-28, 2009.

14. Martins, T.D. Aspectos epidemiológicos da ferrugem alaranjada da cana-de-açúcar. 2011. 65 f. Tese (Doutorado em Fitopatologia) - Escola Superior de Agronomia "Luiz de Queiroz", Piracicaba.

15. Menzies, J. G.; Nielsen, J.; Thomas, P. L.; Long-term storage of Ustilago tritici. Plant Disease, Saint Paul, v. 81, n.11, p.13281330, 1997.

16. Ovalle, W. Comstock, J.C.; Glynn N.C.; Castlebury L.A.; First report of Puccinia kuehnii, causal agent of orange rust of sugarcane, in Guatemala. Plant Disease, Saint Paul, v.92, n.6, p.973, jun-2008.

17. Pérez-García, A.; Mingorance, E.; Rivera,M. E.;Del Pino, D.; Romero, D.; Torés, J. A.; De Vicente, A.; Long-term Preservation of Podosphaera fusca Using Silica Gel, Journal of Phytopathology, Bari, n.154, p.190-192, 2006.

18. Pérez-Vicente, L.; Martín-Triana, E.L.; Barroso, F.; Martínezde-la Parte, E.; Borrás-Hidalgo, O.; Estévez, I.H. Definitive identification of orange rust of sugarcane caused by Puccinia kuehnii in Cuba. Plant Pathology, Broadway, v.59, p. 804, 2010.

19. Salustiano M.E.; Pozza, E.A.; Ferraz Filho, A.C.; Castro, H.A.; Viability of Puccinia psidii urediniospores stored in different environments. Tropical Plant Pathology. Brasília - DF, v.33, n.4, p. $313-316,2008$

20. Zambenedetti, E. B.; Alves, E, Pozza, E.A.; Araújo, D.V.; Germinação de urediniósporos de Phakopsora pachyrhizi em diferentes métodos de armazenamento. Summa Phytopathologica, Botucatu, v.33, n.1, p.83-85, 2007. 